\title{
Issues in Manufacturing Automation \& Robotics within the Past 4 Decades and Vision for the Next
}

\author{
Geza Haidegger PhD., Imre Paniti, PhD. \\ MTA SZTAKI Hungarian Academy of Sciences Budapest, Hungary \\ geza.haidegger@sztaki.mta.hu, imre.paniti@sztaki.mta.hu
}

\begin{abstract}
The past four decades are characterized by the implementation of digital solutions in the production sector, and the advent of robots being used for rigid and fast material handling. This time domain is the implementation phase of the $3^{\text {rd }}$ Industrial Revolution. By today, we can witness the evolution (rather than revolution) of new technologies, that enable far more changes in the digitized factory environment compared to the previous transitions. The authors selected events and episodes from this time-frame to highlight and give appreciation to the pioneers of robotics in Hungary. The authors demonstrate the harmonized vision for the next decade, how the manufacturing in Europe might deepen research in Robotics and in Bio-transition in manufacturing.
\end{abstract}

Keywords-Milestones, success, failures, Technology Platforms, Vision, Strategic Research Agenda, Roadmap

\section{INTRODUCTION}

This summary lecture from the authors is selecting exceptional events from the past 4 decades, from the time when digital technology has enabled the introduction of electronic controllers, mechatronic devices in the production sector, i.e. in the factory environment. With such devices, -as we had called them CNC and PLC controllers very simple mechanical devices, robotic arms with one or two joints, two degrees of freedom (2DoF) or latch machines were controlled rather easily. By designing digital MSI (Middle Scale Integrated) and LSI (Large Scale Integrated) components based sophisticated digital circuits, Hungarian scientists had achieved outstanding world-level success. By the special occasion of the present conference, celebrating the $70^{\text {th }}$ birthday of our professor Imre Rudas, we can happily congratulate to the pioneers of that era, and praise the scientists and professors that had given international recognition to Hungarian scientific results, while also building the strong educational base for teaching and educating the next generation of scholars in robotics. There is only a limited chance even to mention all the outstanding events of these 40 years, so it is a personal and biased selection of great experiences of the authors what is to be mentioned below.

The message to take home is not just a list of events from the past, but also to show the presently active open topics for scientists to solve. At this time in Europe and in most other continents of the world, the governments are pushing and forcing the digitalization of most sectors, like the manufacturing, the education, the governance, etc. Probably the fastest return-of-investment (RoI) will come from the manufacturing and logistics sector, and the social, educational changes probably need more time in this transition. The $4^{\text {th }}$ Industrial Revolution, also treated as reindustrialization, highlights the importance of ROBOTICS, and the need for raising robotics to significantly be a dominant effector of modern production technology.

\section{SELECTED EPISODES OF SUCCES}

\section{A. Implemeting MSI and LSI based controllers}

Middle scale and large scale integrated semiconductor elements were used in the middle of the beginning of the seventies. Interpolator hardware allowed fast and precise control of 2, later on 3 or more axis for driving $\mathrm{NC}$ (numerically controlled) machines. A real breakthrough was achieved when the special interpolator hardware was extended with the support and services of the first microprocessors. The Hungarian DIALOG CNC with advanced human-machine cooperation-oriented dialog technology reached even the US market. US President Mr. Jimi Carter was criticized in the Congress for keeping a strict export regulation for exporting high-tech machines, while witnessing high-tech Hungarian machines being imported to the States.

\section{B. Implemeting LSI, then bit-slice based graphic displays}

By utilizing the very same sophisticated hardware of interpolator, vector-oriented graphic displays were designed to run CAD (Computer Aided Design) workstations. The bit-slice based technology applied in these displays offered to outperform the highest benchmarked IBM displays.

\section{Implemeting local network-based controllers}

Not just our academic institute, but also industrial electric and electronic companies and factories working in cooperation with university teams had shown up very significant control devices: MMG, EMG, VILATI, MOM etc. When machineries got bigger and distributed, the need for local data networks was serviced with novel locally engineered solutions. Very special robotic machines were designed and implemented, like the transporter of fuel-cells in the Hungarian Paks atomic power plant.

\section{Implemeting standards-oriented local networks}

Having witnessed the strong need for being harmonized with high-tech US and West-European technical solutions, research emphasis was placed on getting more involved in international standardization, Based on personal contacts and appreciation of key Hungarian scientists, like professor Joe Hatvany and professor Laszlo Nemes, we had a rare chance to reach the most up-to-date research teams abroad devoted to define a world-standard for factory local area network development. The General Motors Co. directed research focused on the deterministic data transmission technology (MAP Manufacturing Automation Protocol) in opposition to the stochastic systems used by almost every other computer systems at OEM level. In the Eastern Block we, Hungarians were the very first to be able to join those standardization bodies, and influence the local engineers to care for the next generation of upcoming standards. 


\section{E. Joining the EUREKA initiative}

Hungary was the first country in the Eastern Block to join the West-European EUREKA community. The German, British, French and Italian high-level scientists with influence to the local Ministers agreed to inspire international cooperation-oriented tasks for 2 clear benefits: - to skip parallel efforts, and to teach companies how to work within international teams. Financing was given to each participating company by its own ministry. The authors were appointed to support the initialization of such international efforts in the area of factory automation and robotics.

\section{F. Initiating the ManuFuture Technology Platform}

The team of international scientists within the EUREKA FACTORY UMBRELLA pointed out the significant consequence of factories leaving Europe and being set up in the Far-East. The long-term vision was explained to the European Commissioners, and the result was to generate a think-tank for defining the needed steps. Several European Technology Platforms (ETPs) were initiated, collecting all players of a certain field and interest. In former publications [1] more details were given also for the manufacturingrelated ETPs and sub-platforms

\section{G. What have ETS to do?}

European Technology Platforms are industry-led stakeholder fora recognized by the EC as key actors in driving innovation, knowledge transfer and European competitiveness [2].

ETPs develop vision paper(s), research and innovation agendas (SRAs) and roadmaps for actions at EU and national level to be supported by both private and public funding. They mobilize stakeholders to deliver on agreed priorities and share information across the EU. ETPs are independent and self-financing entities. They conduct their activities in a transparent manner and are open to new members.

ETPs are bottom-up driven expert groups, their roles are set in their constitution. Nevertheless, the EP and the EC declared a common set of requirements for ETPs, to define a reliable source for information and Decision Support. Three major documents are required from each ETP to be fed to the EP, EC decision makers. They must be prepared in a straightforward sequence, in harmony with entities involved within the area in a very broad sense:

* To prepare, to develop a VISION document with a time-domain of 10 or $10+$ years, so that the members of that Platform can share the same view for the future explaining it in a harmonized, detailed view.

* To prepare, to develop a Strategic Research and Innovation Agenda (SRA,SRIA), listing what are the missing knowledge and practice solutions building blocks, that are not yet ready, but are in need to apply rather soon in order to reach the Vision, the visional future environment by the end of the next 10 years.

* To prepare, to develop a ROADMAP, that has scenarios for possible best or worst estimates or most probable scenarios, by allocating financial support, manpower and infrastructure parameters together with the time-duration estimates.
ETPS are also responsible to establish a close, industry - academia- and educational partnership, to have balanced view from many domains.

\section{H. ManuFuture ETP with national support from memberstates}

From 2003 to 2004 the European ManuFuture Technology Platform [3] has been involved in the preparation and development of the Vision 2020 document, followed by the SRA in 2006, and finally deployed the ManuFuture Roadmap in 2013 together with the EC's relevant DGs. These docs had been the fundamental stepping stones for the EC and EP to launch the $7^{\text {th }}$ Framework Program and the HORIZON 2020 for a panEuropean joint research-development and innovation program.

As other countries, the Hungarian Government has also been pushed by the EC to help the establishment of National TPs. The Scientific Society for Mechanical Engineers (GTE) [4] had the privilege to be hosting the ManuFutureHU. The NTP in Hungary had prepared the translations of the working documents, like the Vision and the SRA and our Roadmap with national funds estimated for planning as shown in Figure 1.

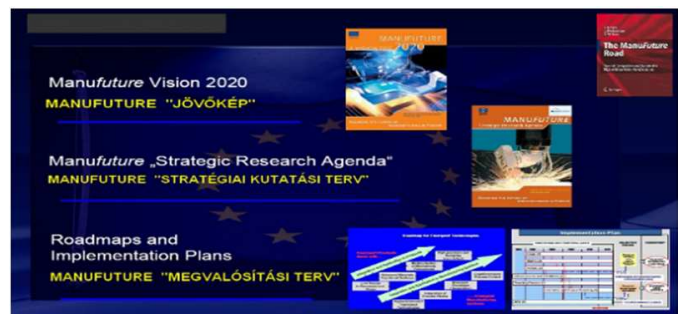

Fig. 1. European and National (Hungarian) ManuFuture main documents (C) GTE

\section{Excellence in FP5, FP6, FP7 and Horizon 2020}

MTA SZTAKI has been a major winner of EU R\&D\&I projects, mainly in the topics of ICT and Factory automation. Many projects have concluded with high-level appreciation. EU Centre of Excellence in Computer Science and Control, Industrial digitization with integration of related technologies has generated a trust with industrial end-users, e.g. with robotic laser-welding, implementing Digital Factory, Digital-TWIN solutions, Industry 4.0 UseCases, or cloud-application in digital factories for rapid prototyping, for one of a kind productions or for small lots [5].

\section{THE PRESENT WORK OF MANUFUTURE ETP}

The ManuFuture ETP has been an active group of 150+ experts and members starting from 15 years back. Even after the deployment of the ROADMAP in 2008, a large group of its members has joined the High Level Group, the Industrial Support Group, the Industrial Advisory Group, the Mirror Group, for strengthening the ETP, for establishing PPPs as EFFRA [6] and for monitoring the progress along the implementations.

During the past 2 years the new version for a new Vision document was developed, that has a foresight timeframe for 2030. The document reached its 'Consultation Version' ManuFuture Vision 2030. In March 2019, the HLG of ManuFuture ETP requested all contributors to disseminate the VISION to all identifiable policy makers. The author 
uses this INES event to address the audience with the findings, and to generate appetite for the reader to get hold of the full text version [7].

\section{A. The structure and content of the Consultation Version} of Vision 2030

The first chapter shows the Manufacturing Industry Today, while Chapter 2 details the megatrends and drivers for manufacturing. Chapter 3 gives vision for scenarios and models for the future manufacturing processes. Vision and strategy are detailed in Chapter 4, and the Vision Building Blocks are described in Chapter 5. A short terminating Chapter deals with Manufacturing\&Society relevancies in the vision. The document is a contribution for political, economic, ecologic, and social orientation from an European perspective.

\section{B. European Manufacturing - global challenges}

This is the backbone of the European economy: with 2.1 million enterprises, employing 30 million workers. Industry 4.0 will impact at global level. Presently Europe is the global leader for the technology and also for its implementation. At international dimensions Europe is the world's biggest exporter, but the decline of added value produced by the manufacturing sector is disturbing, so there is a need to give priority to European manufacturing. Regarding other global areas most of them give high priority to digitization and Key Enabling Technologies, like USA, China, Japan, South Korea, but even South-East Asia.

Competition and cooperation both increase at a global level, and thus the complete manufacturing innovation ecosystem needs to be involved for a change.

Today, society and the world economy are undergoing major changes, driving a social transformation as important as the first industrial revolution. These changes are a global phenomenon, affecting the way we live, work and behave. An unprecedented increase in the speed of development in science and technology, a fast diffusion of knowledge, the scarcity of resources and new generation of consumers will pose challenges and opportunities for Manufacturing. This will lead to a new paradigm shift at a global level.

The following are the most relevant trends and drivers for the future of European Manufacturing (see Figure 2 and Figure 3):

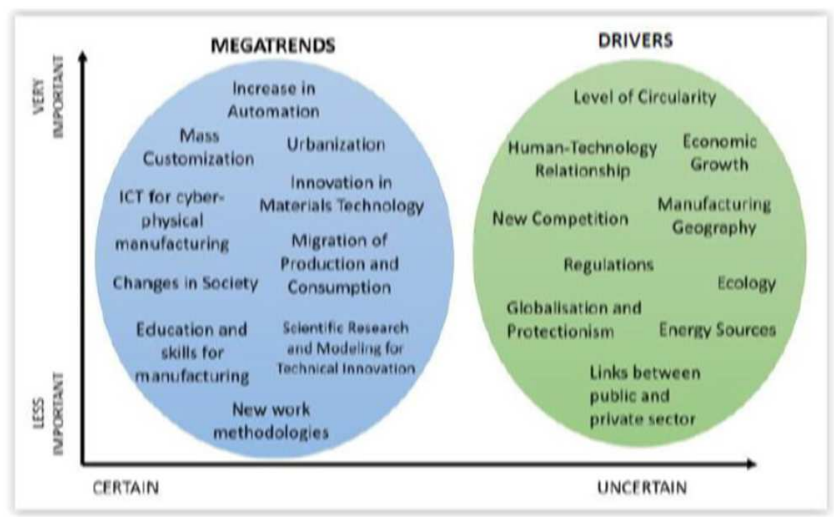

Fig. 2. Megatrends and drivers by importance and certainty. (C)ManuFuture

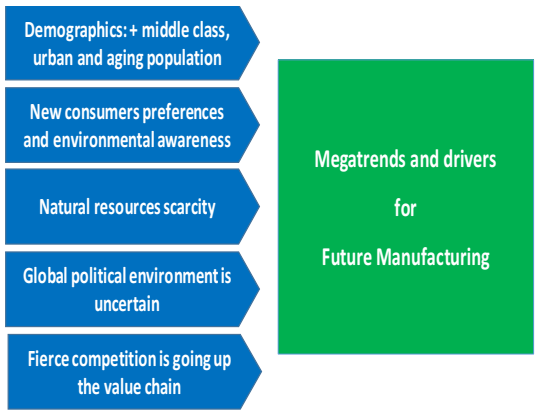

Fig. 3. Megatrends and drivers for future Manufacturing

\section{Future Manufacturing Scenarios and Models}

Understanding the challenges and the foreseen opportunities European manufacturing will have to evolve to exceed the customer's expectations in design, quality and service, and become even more flexible and adaptable. It must be user-centric, the customers will have a central role in the value creation. Bionic manufacturing will enhance and augment relevant human capabilities. Nature inspired manufacturing can lead to new frontiers. Circular economy is a large collaborative endeavor and manufacturing is at its core. Education and life-long learning will become critical functions, and the new concept of learning factories will offer new challenges.

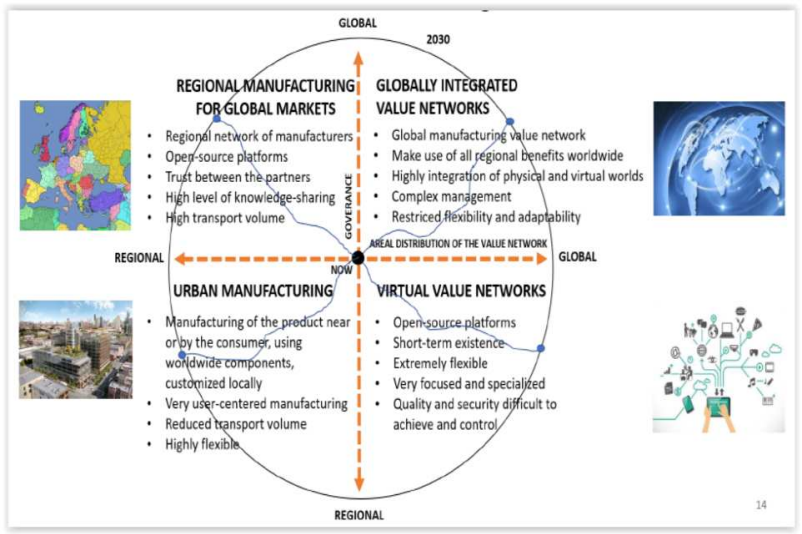

Fig. 4. Scenarios for future manufacturing @ManuFuture

Aligned with the foreseen evolution of manufacturing towards 2030, MANUFUTURE ETP developed four models (see Figure 4) for the development of value networks and manufacturing systems: Globally Integrated Value Networks (Model 1); Regional Value Creation for Global Markets (Model 2); Regional Value Creation for Regional Markets (Model 3); Regionally Regulated Virtual Value Networks (Model 4). Companies will adapt and combine these generic models to optimally address specific market requirements, product characteristics and manufacturing resources availability.

\section{Detailing the RESILIENCE in manufacturing}

From the 2010-s the main priority of manufacturing was set to have competitiveness. During the years 2015-to 2020, the focus was set to have sustainability. In our 2030 vision we estimate to achieve resilience in manufacturing, having the following qualifications: GLOBAL, FLEXIBLE, FAST, MODULAR, NETWORKED, COLLABORATIVE, INDEPENDENT, SUSTAINABLE, COMPETITIVE. Circular economy results in energy- and resource efficiency. 


\section{PREPARING THE StRATEGIC RESEARCH AND INNOVATION AGENDA (SRIA)}

The ManuFuture ETP's High Level Group has already started to work intensively on the SRIA, and plans to deploy it for integrating further, additionally upcoming areas. Declared R\&D\&I priorities are: Manufacturing technology and processes; Digital transformation; Robotics and flexible automation; Nano-technology and new materials; Biological transformation of products, processes and value creation; Customer driven manufacturing; Human Centred Manufacturing; Agile manufacturing systems design and management; Circular economy, resource and energy efficiency; New business logics and models.

Also other ETPs are invited to share and harmonize their own, prepared SRIA elements. The Europe-wide SRIA of ManuFuture ETP is now at a first stage, while the German national SRA has already reached an ARBRIDGED Version level, coordinated and consortium-led by IPA, Stuttgart [8]. Several further ETPs, like euROBOTICS and BigDataValue Association (DBVA) had also been working out SRIAs and even suggested ROADMAPs. As can be seen below joint partnership agreements had been established among these, with a very strong commitment, to address AI as a priority needed for supporting both Robotics, Data Value Creation, Manufacturing, Mobility, Transport, etc. in a plan to create a connected European AI ECOSYSTEM.

\section{A. Robotics}

It was also 4 decades ago, when the Hungarian Robotic MRtT Society was founded. Though it dissolved into other engineering societies, key persons had kept up with innovating: like Prof Imre Rudas had set up robotic labs with special application areas, and initiated a robotics laboratory commemorating Prof. Antal Bejczy, a worldfamous (CALTEC and NASA JPL) robotics expert with Hungarian origin and long-term supporter of the Hungarian education in robotics [IROB]. Between $2012-2017$ this excellent robotic centre had published $320+$ scientific papers. Several scientists and lecturers had the chance to carry out experiments and gain degrees. An excellent example of interdisciplinary topics from Intelligent robotics is on Teleoperation [9], and for AI, Deep Learning a Tutorial Survey should be high-lighted [10].

Important lessons learnt form the AUTOMATICA, the largest European Robotic event bi-yearly in München, where the International Robotic Federation details the growing market for industrial and service robots were: statistics show, that where robots are installed at manufacturing sites, more jobs are opened or created then lost; and that in Europe jobs that are DANGEROUS, DULL or DIFFICULT for humans, there robots MUST BE applied and never humans. This is the "Robotics LAW for 3D”.

Robotic \& flexible automation research, innovation topics are envisages on: Task based programming of robots (including collaborative robots, so called cobots); Intrinsically safe robots; Soft robots; Cognitive and smart robots; Mobile manipulators for logistics; Robot swarms; Drones for manufacturing; Robot machine tool; Shared autonomy in manufacturing - cobots - cooperative manipulation; Robot skill acquisition; Augmenting the human; Reference architectures, Digital Twins, trust\&security, navigation; applications in health care, in agriculture, in construction [11]

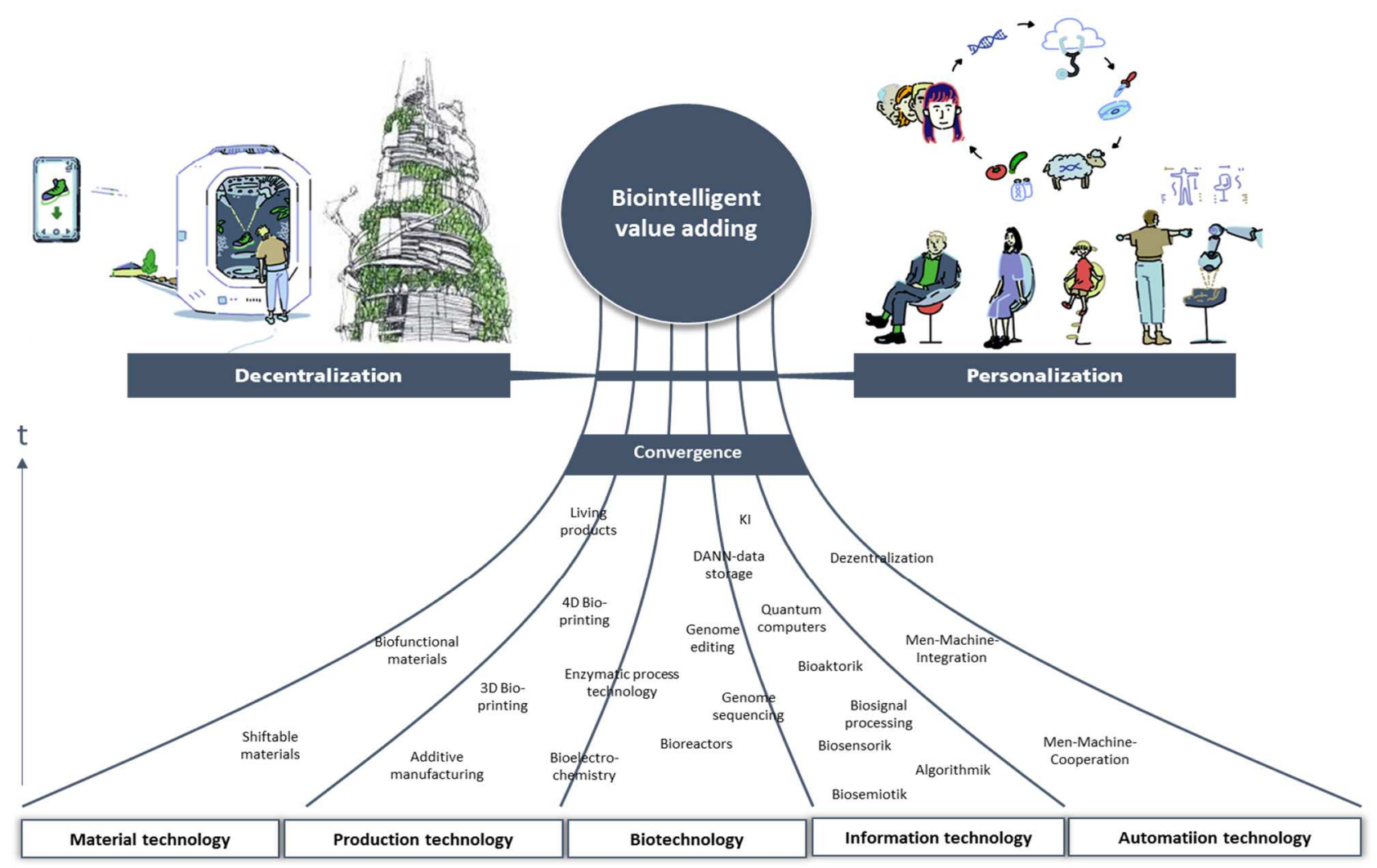

Fig. 5. Bio-transformation of products, processes CIPA 
According to a Market research report of MarketsandMarketsTM the collaborative robot market is estimated to be valued at 12,303 million USD by 2025 , at a compound annual growth rate of $50.31 \%$ between 2017 and 2025. More and more small and medium sized businesses applying Cobots, however safety has become a barrier to the availability of these robotics technologies in all domains, including manufacturing. The reason for this is a number of technical issues (e.g. some robots can change their dynamic behaviour) and due to the interpretation and application problems of current standards. Some projects are working on these issues to help end users with protocols which might involve later on the input of accident insurers, safety verification bodies and national agencies.

\section{B. Biological transformation of products, processes}

The transformation can be discussed in 3 layers: - Bioinspired manufacturing, "INSPIRATION"; -Bio-integrated manufacturing "INTEGRATION"; and Bio-intelligent manufacturing INTERACTION layer.
Biological transformation [12], [13], [14] will produce decentralized or personalized bio-intelligent added value by the integration of technologies and techniques (see Figure 5). Selected research priorities are [13]: Bio-inspired structures, sensors, actuators, additive manufacture of biobased materials, enzymatic processes, micro-bioreactors, smart bio-manufacturing devices, bio-packaging, ecologybased manufacturing, bio-refineries.

Thanks to the digitization of the industry, gathering and storing and evaluating data gets easier and faster. With that, the studying of the living environment brings us closer to be able to understand what is happening around us. By understanding the processes, we might be able to influence and make their production technology more efficient. [15], [16], [17] The German Ministry had realized early the potentials of the biological transformation, and initiated a country-wide BIO-TRAIN project to see a clear picture of challenges and opportunities. This vision of Biological Transformation is shown in Figure 6.

\section{Different aspects of the Biological Transformation|}

\begin{tabular}{|l|l|l|l|}
\hline & Materials & Structures & Processes \\
\hline Substitution & $\begin{array}{l}\text { Fuels and chemicals from } \\
\text { wood-waste and straw } \\
\text { Isobutene production } \\
\text { without fossil fuels }\end{array}$ & $\begin{array}{l}\text { Metallic foam } \\
\text { Highly porous } \\
\text { lightweight material } \\
\text { modeled after bones }\end{array}$ & $\begin{array}{l}\text { Bio-based plastics } \\
\text { plastics, additives and } \\
\text { compounds with } \\
\text { optimal recyclability }\end{array}$ \\
\hline Adaption & $\begin{array}{l}\text { Biomanufacturing } \\
\text { of silk proteins } \\
\text { Industrial scale silk } \\
\text { protein production the lab }\end{array}$ & $\begin{array}{l}\text { Bio-inspired machines } \\
\text { Stress oriented structural } \\
\text { design with carbon } \\
\text { fibers inspired from trees }\end{array}$ & $\begin{array}{l}\text { Self healing materials } \\
\text { Transfer of the self- } \\
\text { healing properties of plants } \\
\text { to technical materials }\end{array}$ \\
\hline Abstraction & $\begin{array}{l}\text { Programmable materials } \\
\text { Targeted adaptation of } \\
\text { materials to environ- } \\
\text { mental changes }\end{array}$ & $\begin{array}{l}\text { Artificial Neural Nets } \\
\text { Neuro-inspired } \\
\text { algorithms with } \\
\text { learning capabilities }\end{array}$ & $\begin{array}{l}\text { Swarm logistics } \\
\text { Transfer of swarm- } \\
\text { intelligence to logistics } \\
\text { systems }\end{array}$ \\
\hline Fusion & $\begin{array}{l}\text { Living cells on microchips } \\
\text { Toxicity-testing with } \\
\text { living cells on physical }\end{array}$ & $\begin{array}{l}\text { Theranostic implants } \\
\text { Medical devices in } \\
\text { symbiosis between tech- } \\
\text { nology and organism }\end{array}$ & $\begin{array}{l}\text { Brain Computer Interfacing } \\
\text { Communication between } \\
\text { biology and technology }\end{array}$ \\
\hline
\end{tabular}

Fig. 6. Biological transformations @IPA

\section{SUMMARY}

This conference paper gave a salute to the pioneers of ROBOTICS in Hungary on the occasion of the $70^{\text {th }}$ birthday of Prof. Imre Rudas, and colleagues. The paper also reflected the present view of scientists on the future of European manufacturing [18], as described in the VISION 2030 of ManuFuture ETP. This short paper also spread upto-date information on the present working process on the strategic research and innovation topics, and a short picture on the future of the European robotics' priorities.

\section{Acknowledgements}

The authors declare, that the VISION for European Manufacturing 2030 document is written and edited by the ManuFuture ETP HLG group members, and this paper is just an appetizer to read the full document. The research in this paper was (partially) supported by the European Commission through the $\mathrm{H} 2020$ project EPIC 
(https://www.centre-epic.eu/) under grant No. 739592. This research has also been supported by the GINOP-2.3.2-152016-00002 grant on an "Industry 4.0 research and innovation centre of excellence". The future research areas, like the biological and robotic areas are acknowledged to be offered by IPA experts listed in the references, but additionally being supported by key scientists Prof. Dr. Ing. Thomas Bauernhansel, head of IPA, Dr. Günther Hörcher, Dr. Marion Früchtl, Dr. Ing. Robert Miehe, members of the HLG of ManuFuture ETP.

\section{REFERENCES}

[1] G.Haidegger, Evolution of technology and users' requirements of factory communication systems from the 3rd to the 4th Industrial Revolution. In: IEEE 2nd International Conference on Telecommunication and Networks, TEL-NET 2017. Noida (Uttar Pradesh), India, 2017.08.10-2017.08.11. NIEEE, 2017. pp. 1-6., ISBN:978-1-5090-6710-7

[2] ETP;https://ec.europa.eu/research/innovationunion/index.cfm?pg=etp

[3] ManuFuture ETP; http://www.manufuture.org/

[4] GTE; www.gteportal.eu

[5] Paniti I. Adaptation of Incremental Sheet Forming into cloud manufacturing. CIRP Journal of Manufacturing Science and Technology. 2014 Jan 1;7(3):185-90

[6] EFFRA, European Factories of the Future Research Association; https://www.effra.eu/

[7] HLG: MANUFUTURE -VISION 2030, consultation version, Competitive, sustainable and resilient European manufacturing, Digital ISBN:978-989-95853-7-9, December 2018

[8] Günter Hörcher, Markus Bessner, Thomas Bauernhansl, IPA: SRIA, . www.ipa.fraunhofer.de/studien

[9] L.Marton, Z.Szanto, T.Haidegger, P.Galambos, and J.Kovecses, "Internet - based Bilateral Teleoperation Using a Revised TimeDomain Passivity Controller," Acta Polytechnica Hungarica, vol. 14. no. 8. pp. 27-45, 2017.
[10] Károly, Artúr István, Róbert Fullér, and Péter Galambos. "Unsupervised Clustering for Deep Learning: A tutorial survey." Acta Polytechnica Hungarica vol. 15, no. 8 (2018): 29-53

[11] Luis Carneiro, INESC TEC, ManuFuture 2030, SRIA, presentation at the HLG Meeting 18-03-2019, www.manufuture.org

[12] Marion Früchtl, Biological Transformation in Manufacturing, ManuFuture HLG, Meeting Milano 08.11.2018.BIO

[13] Robert Miehe, BIOINTELLIGENT VALUE ADDING, ManuFuture HLG Jubily Conference, Milan 2018. November 8 www. Manufuture.org

[14] Bauernhansl, T.; Brecher, C.; Drossel, W.-G.; Gumbsch, P.; ten Hompel, M.; Wolperdinger, M. (Fraunhofer-Gesellschaft zur Förderung der angewandten Forschung e. V.) [Hrsg.]: Biointelligenz - Eine neue Perspektive für nachhaltige industrielle Wertschöpfung - Ergebnisse der Voruntersuchung zur Biologischen Transformation zur Biologischen Transformation der industriellen Wertschöpfung (BIOTRAIN). Aachen, Dortmund, Dresden, Freiburg, Stuttgart, 2019, Fraunhofer-Verlag. ISBN 978-3-8396-1433-4

[15] Miehe R, Bauernhansl R, Schwarz O, Traube A, Lorenzoni A, Waltersmann L, Full J, Horbelt J, Sauer A. The biological transformation of the manufacturing industry - Envisioning biointelligent value adding. Procedia CIRP 2018; 72:739-743.

[16] Miehe R, Full J, Sauer A. Biointelligenz im Produkt und in der Produktion. In: Rieg F: Handbuch Konstruktion. München: Hanser; 2018:621-634. ISBN: 978-3-446-45224-4

[17] Gerald Byrne, Dimitri Dimitrov, Laszló Monostori, et al.: Biologicalisationa: Biological transformation in manufacturing, CIRP Journal of Manufacturing Science and Technology, 21 (2018) 1-32.www.elsevier.com/locate/cirp

[18] Geza Haidegger: VISION2030 on Manufacturing by the HLG of the European ManuFuture Technology Platform, IOP Conference Series: Materials Science and Engineering, 448 012062, GTE XXIII. International Conference on Manufacturing (Manufacturing 2018) Conference, Kecskemét, 7-8 June 2018. 